\title{
IT Evolution: Opportunities for Personal and National Development
}

\author{
Onuiri Ernest E. \\ Department of Computer Science \\ Babcock University, llishan-Remo \\ Ogun State, Nigeria.
}

\author{
Idowu Sunday A. \\ Department of Computer Science \\ Babcock University, Ilishan-Remo \\ Ogun State, Nigeria.
}

\author{
Chioma Patricia E. \\ Department of Mass \\ Communication Babcock \\ University, llishan-Remo \\ Ogun State, Nigeria.
}

\begin{abstract}
The turn of the 21st Century brought with it the Information Age. Over the years, Information Technology (IT) has evolved, producing a lot of breakthroughs in various sectors and bringing about the automation of various processes around the world,therebymaking life easier and more comfortable. It has brought about the sharing of information on a global scale, leading to the growth of developing countries and advancement of already developed countries. This paper takes an exploratory look at the concept of Information Technology, its evolution and effects on personal and national development. Findings suggest that Information Technology platforms and paradigms now pervade all conceivable aspects of human endeavour, and has gone a long way in enhancing and in some cases, optimizing outputs in these areas. These domains of interest include education, health, communication, banking, security, mass media, recreation and tourism, which have all translated into wealth creation both at personal and national levels.
\end{abstract}

\section{Keywords}

Information Technology, Evolution, National Development, Personal Development

\section{INTRODUCTION}

It is without a doubt that giant strides made in the IT spheres have gone a long way in defining how a lot of things are done today ranging from the personal, professional, corporate and national interests. The speed at which information gets disseminated and accessed beats all sort of imagination because looking back in the not too distant past, much of what is in place today could only have been described as "wishful thinking"[1]. However, work is still in progress in that a whole lot of inventions and re-inventions are in the ongoing in different research centres and institutes all over the globe. Hence, one can say that it is only a matter of time and such new technologies will be unveiled. These evolutionary trends explain why IT has come to define as well as find synergies in other fields and specializations. In some cases, this has led to the emergence of interdisciplinary fields such as geoinformatics, telematics, bioinformatics, medical informatics, avionics, bionicsand mechatronics to mention but a few. Today, there is hardly any field of interest that doesn't have a touch of IT in the way and manner it is studied, practiced or operations that take place within it. One very important aspect of this evolution can be seen in the increasing sophistication of artificial intelligence- a field of IT devoted to making machines behave with the sort of intelligence akin to humans. This can be seen in systems where robotics, machine learning, neural networks, multi- agent systems, genetic algorithm paradigms and the likes (the list keeps expanding) have been implemented.

\section{OPPORTUNITIES FOR PERSONAL DEVELOPMENT}

It is pertinent to say that human behaviour and activities have evolved along with the incremental progression that has taken place in the IT domain. This cuts across education, social networking, communication, financial solutions, and access to information, to mention a few.

\subsection{Personal Educational Development}

On the personal level, the evolutionary trends of IT has had its greatest impact in education and learning; as seen in evolving information technologies transforming the nature of work, schools must of a necessity make appropriate changes in their curriculum to reflect the changes technology is making in the workplace.IT has opened the door to a wide variety of learning resources, which heretofore had remain locked except to those who have the adequate financial base to pay for that level of premium education. But as a result of IT intervention, any individual with an internet connected device can receive an education of the highest quality from the comfort of his/her home.

Information they say is power. Today, top universities of the world are offering recorded class sessions online free of charge for anyone who cares to benefit from it. A typical example is MIT Open Courseware and the Harvard Extension Classes. A myriad of other free high quality learning resources by top notch universities are made available at websites such as www.coursera.org, www.udacity.com.Furthermore, with the support of IT, it is now stress-free to deliver an audiovisual dimension to the learning process, the learning resources are increasing in capacity; as a consequence of this expanse, learners are fortified to regard computers and computing devices as tools to be used in all facets of their studies.

A paradigm shift in learning which until recently was seemingly unpopular is "Distance Learning" which is a way of learning at a distance as opposed to the traditional classroom setting. Distance learning broadens access for students incapable for whatever reason (course availability, geographic remoteness, family circumstances, individual disability etc.) to study alongside others. Simultaneously, it pleas students who fancy learning at home[2]. IT has amongst others provided a highway traffic for information flow as information needed to affect decisions made on a daily basis are being delivered at the very great speeds such as weather forecasts, market information, to mention just a few. 


\subsection{Communication and Information Access/Dissemination}

Until the late twentieth century, the concept of unified communication was unheard of. It was definitely unnecessary. However, at the turn of the twenty-first century, IT evolution gave rise to the overwhelming demand for integrated communication where information in various forms such as emails, telephone, SMS, video conferencing, instant messaging are all managed by a uniform platform. A major feature of this technology is the segregation of data requiring real-time support from those requiring non-real-time support. An instance of this is Microsoft's office communicator [3].

In addition, there is so much buzz about social media which has increased the speed with which information dissemination is carried out. Some of these include: Facebook, Twitter, Google+, Instagram, Skype, YouTube and LinkedIn. Most times they are used as tools to express opinions especially in opposition to unaccepted governmental policies, crime, corruption and matters pertaining to the "current affairs" of the nation or community of interest. A typical example of this is the rate at which people got mobilized in the wake of the revolutions that swept through some Arab countries between 2010 till date, such as Tunisia, Morocco, Libya, Egypt and Syria. On May 28, it was all over the international media thatthousands had taken to the streets in Istanbul, Turkey in solidarity with the environmental activists who opposed the government's intention to convert a relaxation area to a mall. All it took was some postings on social media which soon escalated into a national crisis that persisted for months before a truce was reached.

In Nigeria, observation shows that information sometime gets disseminated at similar speed in recent times when the government removed the subsidy on fuel in January 2012 as well as when the name of University of Lagos was changed to Moshood Abiola University in the first quarter of 2012. Also witnessed was the barbaric killing of four students of University of Port Harcourt in the last quarter of 2012 and the hullabaloo that engulfed the Rivers State House of Assembly in July 2013 to mention but a few. In view of the foregoing, there is no gainsaying the fact that some of the outcries by the masses to governmental agencies have yielded positive result. However, there have been instances where the relevant agencies chose to remain adamant.

Also, some news stations with global presence such as CNN, $\mathrm{BBC}$, Aljazeera and Channels now have online presence which implies that people can have access to news items especially "breaking news" while on the fly without need for a television and other connections which hitherto was the only means through which such access was possible. Telephony has gone from the crude analog systems and methods to more of digital and efficient systems leading to technologies that support the likes of $4 \mathrm{G}$ communicationthrough voice over internet protocol (VoIP). By this, communicators are not only assured of voice communication but live video of the one being communicated and to think of the efficiency with which this is implemented over the already existing and robust internet protocol makes it the more fascinating. It is this platform that applications such as Skype, Google, and Yahoo are currently exploiting to the amazement of the users.

Chat applications cannot be left out of this frenzy as they play a major role in especially giving users an alternative to voice communication while being assured of real-time communication with their target audience which could be a single user or group. Examples of these include the
Blackberry Messenger, Whatsapp, Nimbuzz, 2go to mention but a few. In this part of the world where mobile operators spend huge sums of money to facilitate their networks, users are made to bear the brunt of this overhead, leading to high cost of communication. Hence, chat applications stand in the gap to ensure communication takes place on the cheap and all it takes is to have the application installed on the mobile device, minor configurations and end-to-end communication ensues.

\subsection{Recreation/Relaxation}

Temple Run, Angry Birds, 4pics 1 Word, Subway Surf, Candy Crush, etc. these names have become household names in the ever-changing field of gaming. The evolution of IT has brought with it new ways of recreation right such that people no longer have to go to recreation centers to play a good game;they can now be downloaded on hand-held devices keeping their users engulfed in their storyline, twists, turns and amazing gaming environments.Another dynamic characteristic of today's games is that they can be configured to compete with other gamers on different hand-held devices via the internet known as online gaming. Games such as scrabble, Pro Evolution Soccer (PES), Need for Speed (NFS), FIFA 2014, GTA (Grand Theft Auto) etc. have such features.They also have features that enable you broadcast your high scores on social networking sites like Facebook and Twitter increasing the fun as friends could comment on your performance. Research has proven that games help to promote faster and more precise attention allocation, advanced spatial resolution in visual processing, hand-eye coordination and improved mental rotation capabilities [4].

Nigeria has taken technological recreation to the next level with the development of applications that relate to various aspects of life. For example, Iroko TV, a platform that provides Nigerians both home and abroad with Nollywood movies, ensures easier access. This implies that rather than the usual dependence on the distributors of these movies to purchase them, this can now be achieved from home or any other place of comfort.Also, applications such as "owe" that relate to cultural and traditions like proverbs in the three main Nigerian languages, traditional names and meanings, traditional recipes etc., are now available. The comedy industry is not left out in this new wave. Famous comedians like AY, Basket mouth, now have applications that provide users with a never ending source of their rib-cracking jokes. An example is Akpos jokes. Furthermore, blogging has also become common place in society, famous blogs like the Linda Ikeji Blog, Ladun Liadi blog, Bellanaijia are providing Nigerians with non-stop information and exciting gossip about their favourite stars and politicians. Followers of these blogs also have the ability to comment on featured stories and comments of other followers, providing the much needed excitement and giving ordinary Nigerian a voice.

Personal development has taken a new dimension with the new trends in IT bringing about limitless possibilities in the way people improve on themselves.

\subsection{Wealth Creation}

The ability to create an avenue for a constant source of income to meet ones needs is the greatest power that can be given to any individual. Evolution of IT has taken entrepreneurship to the next level. So many tech startups have landed their CEOs on the list of the world's richest, and have gone on to become fortune 500 companies. The founders of Google, Amazon, Facebook, Twitter, Tumblr andInstagram 
are glaring examples of people who have used IT as a platform for wealth creation.

In recent times, Nigerian Entrepreneurs have continued to key into IT buzz leading to the establishment of successful companies. Jumia, Konga, Kuluya, Kasuwa and IrokoTv are examples of companies that have been established on the IT platform. The Chief Executives of the above listed companies have not only set themselves on the path to becoming the richest men in Nigeria and Africa but have also become employers of labour. Furthermore, the administration of their companies have led them to acquire skills that would help them grow the company, skills which they would not have possessed without the establishment of these companies.

\section{OPPORTUNITIES FOR NATIONAL DEVELOPMENT}

Over the years, the challenge of National improvement in Nigeria and the solution has been a subject of intense debate. Walter Rodney perceives national growth as one tantamount to the capacity of the citizenry make use of technological tools to master their environment in pursuit of their needs, solving their problems, and advancing their society as well as their possession of the capacity to regulate their internal and external relationships[5]. Evidently, the desirableprogress and advancing economic trendsevidenced in numerous Asian countries have been robustly documented. "The only region in the world that has been able to uphold strong, steady growth patterns over several decades, led first by Japan and the newly industrializing economies of Hong Kong, South Korea, Singapore and Taiwan, etc.is East Asia" [6].

Quite a number of other factors account for therapid advancement witnessed in the aforementioned societies apart from their homogenous nature. "These are:growth of the agricultural sector, a system of mass education, growth of local industries, export-oriented strategy, the Spartan discipline of their leadership, existence of effective bureaucracy, human resources development, encouragement of a dynamic private sector working in co-operation with the government towards a society-wide vision of development, institutional ability building and attention to the problems of governance, consistency and policy stability, etc."[7]All these were formed upon the IT evolution in those countries.

These countries highlighted abovehave consequently invested heavily in IT and have in most parts, gained a reputation as technological giants. Nigeria has an abundance of human resources to follow this East Asian national growth model. Growth in human resources has been identified as a magic bullet to the national development of Nigeria; this premise is based on results obtained in both the Japanese and South Korean climes, where individualdevelopment brought about a resultant change in the country's fortunes. Generally speaking, the concept of development can be associated with knowledge and skillsacquisition, such that anextraordinary educational quality and capacity for training is attained for most of the populace in a cost effective way, such thathigh level educational exposure is guaranteed in order to measure up to the developmental needs of the entire nation. "Works on development stresses the axiom that it is the people who develop and that unless there are large numbers of suitably qualified people, development cannot take place" [7].

There need for attitudinal change is also sacrosanct, hence the need for people to adopt an optimistic attitude towards development. The idea or belief in some developing countries that things cannot work should be dispirited. Factual development is attained through internal activities rather than from external influences. Development is seen as a procedurespawned within a society by forces promulgated and invigorated by the actual members of that society. True development cannot be started nor sustained by outsiders. Though, no country can progress in separation, emphasis cannot and should not be placed on foreign resources for the country's development. The prevalent and widespread tool of IT can be harnessed by adopting the models of development of Japan and China in utilizing their in-house/internal resources both human and material for swift economic development. It is rational that developing countries should adopt a high sense of patriotism as demonstrated by the Japanese and Chinese [7].

Consequently, there are quite a number of facets that national development can be engendered as orchestrated by the ever evolving trend in IT. Some of these include but not limited to the following: infrastructural development, telecommunication, education, health, industries (automation), agriculture, stock exchange/forex trading, banking, ecommerce, interdisciplinary/inter-platform synergies, and innovativeness.

\subsection{National Educational Development}

It is no longer news that advanced societies as well as those that are growing very fast have for long placed a high premium of investment in their educational system. Countries like Canada, Norway and Finland can boast of more than $60 \%$ of their respective populations as educated up to university levels. It is this sort of statistics that have made them one of the most advanced economies ranking very high in most indices with which the wealthiness or poorness of nations are adjudged. Many progressive nations have since keyed-in to this drive and have over time upped their budget provisions on education. Research grants and funding are made available to professors on a yearly basis to fuel scientific and innovative discoveries, inventions and improvement on already existing ones. This intentional educational advancement is such that their citadels of learning make it possible for sophisticated research in the areas of IT amongst others. It is in most of these labs that innovations are conceived, nurtured and born to the ovation of the consuming world like Nigeria.

\subsection{Electronic Commerce}

Who would have thought that the simple process of buying and selling; of shopping would one day be automated? Instead of having to go to the mall or the grocery shop, to get supplies, one can shop from anywhere just with the click of a button. This is the luxury that IT has brought to the world of commerce, providing a virtual platform for the promotion of trade. Hence,the name E-commerce or Electronic Commerce. In this field of e-commerce there are fortune 500 companies like Amazon, Ebay, Alibaba who have distinguished themselves and have now become household names not just in the United States but globally, as deliveries are made as far as Africa and Asia. They have not only created wealth for themselves, but make huge contributions to the GDP of United States, thereby boosting their economy.

In view of the foregoing, Nigerians have also taken the bait and have set up various e-commerce driven businesses which have distinguished themselves and have made it obvious that they are here to stay. The likes of Jumia Nigeria, Konga Online Shopping Limited, Olx, all indigenous e-commerce startups that have become full blown companies, providing job opportunities for hitherto unemployed youths, contributing their own quota to the Nigerian economy.They 
have provided a means for Nigerians to join the rest of the world to shop in comfort, providing quality goods at reasonable prices and various payment methods. Without a doubt, the number of e-commerce companies would increase in Nigeria, providing the required competition that helps in the developmental process of any sector of the economy.

\subsection{Banking}

The saying goes, "Where your money is there lies your heart" The banking Industry in any country is therefore important. Various banking processes with the help of IT have been automated making it easier for both customers and bankers to have smooth and hitch free transactions. It has also enabled banks to provide utmost security features for their banking processes which also helps them keep abreast of daily transactions thus making it easier to make forecasts and company decisions. Also, ATMs(Automated Teller Machines) have emerged, making it easy for customers to withdraw money from their accounts without having to wait on long queues in banking halls. Companies like MasterCard, Visa and the Indigenous brand Verve from Interswitch Nigeria have made e-business so easy.

Transfer of money from one country to the other and one continent to the other is another impressive feature that IT has provided on the banking scene. People are now able to send money to recipients all around the world through platforms like the Western Union Money transfer, MoneyGram etc. In addition, the evolution of IT has brought with it various banking innovations that make the process even more comfortable and exciting for both the banking institutions and the customers with the emergence of Internet banking platform, the SMS Alert feature, POS (Point of Sale) terminals, etc.The world is gradually evolving into a cashless society, using electronic cards to conduct business transactions via various platforms. Nigeria is not left behind in this new wave as policies from the Central Bank of Nigeria have been drafted into the Nigerian Economy. Internet Banking/E-banking Systems from different banks in Nigeria like FirstMoney from First Bank, GTB mobile money from Guaranty Trust (GT) Bank, eaZymoney and Zmobile, from Zenith Bank, Straight2Bank from Standard Chartered Bank etc.are making the cashless policy a reality.Also, account information can be retrieved anytime and this can be done from any location that enjoys network coverage [8]. Security on these platforms is provided using Tokens which provide one time passwords(OTP). OTP is a secure framework, designed for logging on to a network or service with the use of a one-off password that cannot be reused. This avertsthe various forms of identity theft by ensuring as well as guaranteeing that a username/password combination cannot be reused. The login name of the user remains the same, and the OTP changes with each login. OTPs is an innovative form of strong authentication, which provides a more effectual protection to online banking and financial services which are highly associated with very sensitive data [9].

The use of POS has become widespread across merchant locations all over Nigeria.A POS machine is used to execute financial payments for retail transactions as well as related services. The services, depending on the model includes credit card processing, cheque reading and cash payments. These devices are often found in grocery stores, fuel stations, restaurants etc. POS machines offer the ability to computerize many tasks that hitherto traditionally required the supervision of humans. POShas the ability to scan credit cards, authorize the charge, as well as accept a digital signature. POS machines can also syncwith the local networks of the businesses, and automatically update balances and inventory in real time [10]. Most businesses have bought into the cashless society dream of the CBN (Central Bank of Nigeria) making it possible for their customers to pay via POS machines.

Alsopayment of bills have taken a new dimension on the global scene as online payment platforms like Paypal, Google Checkouts, Square, Quickteller from Interswitch Nigeria, Etranzact, Unified Payments-a subset of e-commerce which facilitate the acceptance of electronic ideas for online transactions, enabling customers pay their bills at the click of a few buttons[11]. Quickteller supports payment of bills under various categories some of whichinclude:airtime recharge,religious institutions,schools, transport and toll payments, event tickets association membership dues, donations etc. that were hitherto only conducted by accessing the payment systems for the various organizations [12]. However, right now, all these companies can be represented on one payment platform providing the renowned convenience that IT brings for both customers and organizations.

\subsection{Security}

CIA (Central Intelligence Agency), INTERPOL (International Criminal Police Organization), SCOTLAND YARD etc. have increased the efficiency of their organizations with the help of IT in the field of security. Centralized Database systems help them find synchronizations between new and old criminal cases. It also helps them to make predictions, find fingerprint matches and criminal profile matches. Some of the software used include Intellipedia, IAW-Intelligent Agent Workbench, Link-Analyses by Ancapa Sciences, Palantir Government by Palantir Technologies and Oasis by CIA, Policeware. These platforms provide integrated analyses of huge amounts of data at varying levels of classification across many different agencies in a highly effective way and could also help to convert intercepted audio into searchable text [13]; Forensic analyses have also been made possible with IT in this field. Some of the software systems used for forensic analyses include: CAINE-Computer Aided Investigative Environment, The Sleuth Kit, Oxygen Forensic Suite help to provide impartial scientific evidence for the court of law [14]. IT plays its part by increasing the ability of law enforcement agencies in protecting life and property on a global scale.A society with controlled crime rate is an investor-friendly environment which helps to increaseFDI (Foreign direct Investment), boosting a country's economy which is made possible by anIT-oriented security system.

\subsection{Tourism}

Malaysia-Truly Asia, Maldives-The sunny side of life, Cyprus-In your Heart, India-Incredible India etc. have ridden on the wings of IT to project their countries and their respective attractions to the world. These slogans have been made possible as a result of their online presence with official websites of their ministries of tourism like www.tourism.gov.my, www.visitmaldives.com, www.visitcyprus.com, www.incredibleindia.org offering information to prospective tourists on the beauty and warmth of their country and its people. The increase in the penetration of the Internet into the nooks and crannies of countries around the world has made it possible for exportation of culture. This means that information about beautiful vacation spots and tourist attractions can be gotten by accessing the website of these countries. The availability of these websites produces an increase in influx of tourists to these countries contributing to the growth of their economy.Nigeria is not left behind as the 
website of the ministry of tourism, tourism.gov.ng, helps to project the beauty of the country and the warmth of its people to the world.IT in the field of tourism has helped in the interconnection of nations of the world.

\subsection{Satellite Communication}

Prior to the 21st century, the concept of launching satellites into space for the purpose of communication and surveillance was unheard of. However, with the evolution of IT there are now about 20 satellites orbiting the earth. These satellites are for different purposes such as weather satellite for weather forecast, communications satellite for live radio, television and telephone transmissions anywhere in the world, navigation satellites and space exploration satellites. Certain agencies in the world are renowned for their prowess in this field and their contribution to the advancement of IT remains beneficial. Some of these agencies include, National Aeronautics and Space Administration(NASA) responsible for allthe science and technology in the USA especially those related to aeronautics and space exploration [15].In 2009, Nigeria launched the NIGCOMSAT (Nigerian Communication Satellite), taking its place on the list of countries with a satellite in space. Thereplacement satellite for NigComSat-1 Satellite is NigComSat-1R. "NigComSat-1R is a critical ICT support infrastructure to drive the National ICT revolution in providing revenue diversification for the nation and offering cost effective solution and affordable access to meet Nigeria's telecommunications, broadcast, aviation, maritime, defense and security needs" [16].

These satellites help in the building of a GIS (Geographical Information System) that can help in the tracking and monitoring of events that take place in the country such as distance learning, internet trunking, rural telephony, Voice over Internet Protocol (VOIP), telemedicine, television broadcasting, and Video on Demand (VOD) [17]. Satellite technology can offer valuable information in a number of areas from business to disaster management to agriculture in the areas of remote sensing, communication, and navigation. There is countless potential for such technology to help solve problems in in various sectors of the economy and it can help to maximize the contribution of these sectors to the GDP (Gross Domestic Product).

\subsection{Mass Media}

IT has fostered an overhaul in media management,and operations. It is the driving force ofvirtually every aspect of the media; providing technology through which traditional media (newspaper, radio, and television) have come toeffectively improve upon theirsurveillance function of the society for newsworthy information and occurrences through the digitalization of its news gathering, production and delivery. With technology such as: the internet, satellite, cable data transmission, digital cameras, Global System of Mobile Communication (GSM), information gatheringand dissemination has become timelier. For instance, print media organizations in Nigeria have been largely transformed as journalists carry out their function of information gathering and editing with ease digitally, production is facilitated through digital printing thereby fostering timely circulation of the dailies, not to mention better quality and cost effectiveness [18]. They no longer solely relay on mainstream television tube, radio set, and newspaper tabloid to disseminate information to their audiences, but augment these channels through webcasting, and online circulation which provide more income, wider audience reach, as well as afford the audience access to information at their convenience. Also, through email, text messaging, and social media such as:
Facebook, Twitter, LinkedIn, Instagram, audience members can send feedback and participate at various levels of media discourse.

In recognition of the immense contribution of IT to the development of the mass media, many countries around the world have acknowledged the need for the digitization of the broadcast media whereby every media organization is expected to shift from analog to digital broadcasting, and as a matter of fact, a June 17, 2015 was set by the International telecommunication Union (ITC) in 2006. In 2007, the Nigerian government under the leadership of late President Umaru Yar'Adua gave approval directing the National Broadcasting Commission (NBC) to pilot the digitization of broadcasting in Nigeria [19]. . NBC is the governing body for broadcasting in Nigeria. Although a June 17, 2010 deadline was set by the NBC, it is yet to totally materialize.

\subsection{Healthcare}

Health they say is wealth. The importance of a healthy population cannot be overemphasized as the development of any nation relies on its human capital. Administration of health related processes has taken a turn for the better with the advent of breakthroughs in the world of IT. The most direct contribution of IT to improving the valueand quality of healthcare is providing the clinician with adequate information about the patient, health problems at hand, alternative tests and treatments especially at the point of care. Application areas include: Electronic Health Records(EHR), Health Information Systems like MEDLINE-USA National Library of Medicine, SCORPIO-USA Library of congress and Clinical Decision Support Systems (CDSS) which are knowledge-based systems designed for clinical use like HELP (Health Evaluation Through Logical Processing) by 3M Co. and RMRS (Regenstrief Medical Record System) by Indiana University.These applications can potentially improve the quality of healthcare by enhancing clinical decision support and improving data for accessing health services and the performance of health care services and the performance of healthcare providers and insurance plans [20].

\section{RECOMMENDATIONS}

The evolution of IT brings with it tremendous benefits that can promote National and Personal development as seen in the various examples highlighted in this article. However, there is still room for improvement, as the benefits can be harnessed to produce a more profound effect on boththe personal and National scale.

IT can be used to create National Database Management Systems for effective planning and communication amid citizens at home and abroad, for government agencies like Independent National Electoral Commission (INEC), Federal Road Safety Commission(FRSC), Internal Revenue Service (IRS), defense and law enforcement.

The use of electronic media in government processes will help to simplify citizens' access to the process of governance andgovernment information by providing options forInteraction with government and government contract tendering and procurement processes. This would lead to accountability, promote transparency and strengthen democracy thereby fostering National Development.IT can be deployed in the Health sector for the enhancement of drug information records, bibliographic records and for the study and control of epidemics.

In addition, the government should capitalize on existing global IT infrastructure such as the free"Healthnet Satellife". 
Satellife is a dais that encourages the use of informationtechnology for better health in low-resource environments by engaging the use of mobile computing devices for information dissemination and data collection. It linksmedical personnel in the developing world to each other at all levels, and helps to select health experts in developed countries. Countries using this infrastructure include:Uganda and Mozambique with their Uganda Health Information network(UHIN) and Mozambique Health Information Network (MHIN) respectively [21]. This would go a long way in improving the quality of Health care delivery in Nigeria, a template for which can be replicated in countries in the same socio-economic bracket as Nigeria.

The use of IT in the establishment of an Agricultural Information Systems to provide support for planning, production, storage and distribution of, horticultural crops, livestock and fishery products. This will help re-engineer agriculture for the purposes ofmaximizing food production, improving food self-sufficiency andsecurity, increasing output for industrial raw material utilization,providing employment, economic growth and minimizing environmental abuse and degradation.

\section{CONCLUSION}

IT is the base of both personal and national development in this rapidly changing global environment. With this evolution comesso many benefits that can be utilized to create a suitable climate for the automation of many processes,thereby making life easier and more comfortable. To be successful in this information age as a person, enterprise or nation, it is important to view IT as a strategic asset for achieving personal, business and national goals. There is need for a paradigm shift inmatters pertaining to IT from tactical to strategic, in order to effectively integrate the new dimensions that its evolution engenders, so as to deliver new applications in different areas for a faster, easier and more comfortable lifestyles.

\section{REFERENCES}

[1] Waldman S. (2011). The Information Needs of Communities - The changing media landscape in a broadband age. www.fcc.gov/infoneedsreport. Retrieved March 3, 2014.

[2] Garrison R. (2000). Theoretical challenges for distance education in the 21st century: A shift from structural to transactional issues. International Review of Research in Open and Distance Learning, 1(1), 1-17 http://www.irrodl.org/index.php/irrodl/article/view/2/333 . Retrieved March 3, 2014.

[3] Onuiri E.\& Awodele O. (2012). Quality of Service in Unified Communication. International Journal of Advanced Research in Computer Science and Software Engineering.

[4] Granic I., Lobel A. \& Engels R. (2012). "Benefits of Playing Video Games" in www.apa.org Retrieved February 18, 2014.

[5] Gilani I.S. (2008). Project on Business and Politics in the Muslim World - Second Quarterly Report on Africa.
www.gilanifoundation.com/homepage/...09/.../3-AfricaJUNE-2008.pdf. Retrieved February 26, 2014.

[6] Indermit S. G. \&Homi K. (2007). Ideas for Economic Growth. http://elibrary.worldbank.org/doi/abs/10.1596/978-08213-6747-6. Retrieved February 26, 2014.

[7] Lawal T. \& Oluwatoyin A. (2011). National development in Nigeria: Issues, challenges and prospects. Journal of Public Administration and Policy Research Vol. 3(9), pp. 237-241, November 2011. Available online http://www.academicjournals.org/jpapr. DOI: $\quad 10.5897 / J P A P R 11.012$. ISSN 2141-2480. Retrieved February 26, 2014.

[8] Investor Words (2011). "Online Banking" in www.investorwords.com Retrieved February 4, 2014

[9] Gemalto (2011). "One Time Password (OTP)"in www.gemalto.com/techno/otp/ Retrieved February 17, 2014.

[10] Enne V. (2011). "Definition of POS Machine" in www.ehow.com Retrieved February 12, 2014.

[11] E-payment (2010). "E-Payment Systems" in www.epayments.com Retrieved January 31, 2014.

[12] Interswitch Nigeria (2014). "Quickteller" in https://connect.interswitchng.com/ Retrieved February 4, 2014.

[13] Defense News (2007). "US Intel Agencies modernize Info Sharing" in www.defensenews.com. Retrieved February 5, 2014.

[14] Digital Intelligence (2012). "Forensic Software" in www.didgitalintelligence.com Retrieved February 7, 2014.

[15] NASA (2013). "About NASA" in www.nasa.gov Retrieved February 7, 2014.

[16] NIGCOMSAT (2013). "NIGCOMSAT Limited" in www.nigcomsat.com Retrieved February 18,2014.

[17] Intelsat (2013). "Satellite Technology for Communication" in www.intelsat.com Retrieved February 19, 2014.

[18] Ufuophu-Biri, E. and Ojebode, A. (2012). Usage of Information Communication Technologies and Job Motivation among Newspaper Workers in Nigeria in Journal of Communication and Media Research Vol.4 No.1,pp. 129-142

[19] Idoko, O.E. (2010). The Challenges of Digital Television Broadcasting in Nigeria. https://makurdijournal.wordpress.com/blackboard/broadc ast-seminar/msc-papers/papers-on-digital-broadcasting/ Retrieved March 17, 2015

[20] Medpac (2004). "Information Technology in Healthcare" in www.medpac.gov Retrieved February 18, 2014.

[21] FHI-360 (2011). "SATELLIFE-Moving Information to the Hands of those who heal" in www.healthnet.org Retrieved February 18, 2014. 